\title{
A reference map and identification of porcine testis proteins using 2-DE and MS
}

\author{
San-Yuan Huang ${ }^{1}$, Jyh-Hung Lin' ${ }^{1}$ Yu-Huey Chen ${ }^{1}$, Chin-kai Chuang ${ }^{1}$, \\ En-Chung Lin' ${ }^{2}$,Mu-Chiou Huang ${ }^{3}$, Hsiao-Fang Sunny Sun ${ }^{4}$ and Wen-Chuan Lee ${ }^{1}$ \\ ${ }^{1}$ Division of Biotechnology, Animal Technology Institute Taiwan, Taiwan, Republic of China \\ ${ }^{2}$ Department of Animal Science, National Taiwan University, Taiwan, Republic of China \\ ${ }^{3}$ Department of Animal Science, National Chung-Hsing University, Taiwan, Republic of China \\ ${ }^{4}$ Institute of Molecular Medicine, National Cheng-Kung University, Taiwan, Republic of China
}

The development of the testis is essential for maturation of male mammals. A complete understanding of proteins expressed in the testis will provide biological information on many reproductive dysfunctions in males. The purposes of this study were to apply a proteomic approach to Revised: January 11, 2005 investigating protein composition and to establish a 2-D PAGE reference map for porcine testis proteins. MALDI-TOF MS was performed for protein identification. When $1 \mathrm{mg}$ of total proteins was assayed by 2-D PAGE and stained with colloidal CBB, more than 400 proteins with a $\mathrm{pI}$ of $\mathrm{pH}$ 3-10 and $M_{\mathrm{r}}$ of 10-200 kDa could be detected. Protein expression varied among individuals, with CV between 4.7 and $131.5 \%$. A total of 447 protein spots were excised for identification, among which 337 spots were identified by searching the mass spectra against the NCBInr database. Identification of the remaining 110 spots was unsuccessful. A 2-D PAGE-based porcine testis protein database has been constructed on the basis of the results and will be published on the WWW. This database should be valuable for investigating the developmental biology and pathology of porcine testis.

\section{Keywords:}

2-DE / MALDI-MS / Porcine testis / Protein database / Proteome

\section{Introduction}

The development of the testis is an essential event for reproduction in male mammals. The major functions of the testis are synthesizing androgen by Leydig cells and producing sperm cells [1]. The process of testicular development involves change of gametocyte morphology, called spermatogenesis, and endocrine regulation [2, 3]. The development of boar testis can be divided into three stages: the first occurs

Correspondence: Dr. Wen-Chuan Lee, Division of Biotechnology, Animal Technology Institute Taiwan, P.O. Box 23, Chunan 350, Miaoli, Taiwan, Republic of China

E-mail: wen-chuan@mail.atit.org.tw

Fax: +886-37-585829

Abbreviation: HSPs, heat shock proteins early in gestation $[4,5]$, that is before 35 days of gestation; the second begins 3 wk before parturition, continuing until approximately 3 wk postnatally [4, 6, 7]; and the third begins at approximately 90 days of age through puberty $[4,8]$.

Many proteins are massively expressed in the testis, including isozymes (such as lactose dehydrogenase, cytochrome $c$, and protein kinase), cytoskeletal proteins (such as tubulin, acrosin, and histone), products of proto-oncogenes (such as c-raf, ras, and c-abl), heat shock proteins (such as HSP70), and cAMP-regulated kinases, enzymes, and transcription factors [9]. These proteins play important roles in spermatogenesis.

The term "proteome" was first coined by Wilkins et al. [10] to describe the protein product of a genome. External, internal, and micro-environments make a proteome much more complex than a genome. Characterizing the overall expression of a proteome will be helpful for exploring 
interactions between genes, environments, and proteins [11]. Proteomics relies on techniques including high-resolution 2-D PAGE in combination with MALDI-TOF MS and LC-MS/MS [12]. Blackstok and Weir [13] conceptualized proteomics for the global analysis of gene expression at the protein level (including level of expression, PTM, and interactions between proteins). Proteomics, now defined as large-scale analysis of the functions of genes, is becoming central to functional genomics [14]. The study of proteomics will deepen the understanding of protein functions and will have valuable applications in clinical and biomedical fields [13].

Mapping tissues crucial in reproductive function (e.g., testis, ovary, and placenta) will facilitate examination of the effects of protein expression level on reproduction [15]. Several investigations have applied 2-D PAGE to compare proteins synthesized by meiotic and post-meiotic germ cells in rodents [16-18]. However, few studies have explored proteomes of whole tissue of the reproductive tract. The authors of the present study investigated the effect of specific protein expression on male semen quality [19, 20] and applied proteomic approaches to analyzing developmental changes of HSPs in porcine testis (submitted for publication). Studies of testis protein expression at various developmental stages and under different physiological conditions constituted the central theme for exploring porcine reproduction. The present study applied a proteomic approach to analyzing protein composition, constructing a 2-D PAGE protein reference map for normal mature porcine testis. The map contained more than 447 protein spots. Altogether, 337 protein spots were identified by searching peptide mass spectra against the NCBInr database. Information from identified proteins was then employed to construct a 2-D PAGE protein database for porcine testis. This database, which will be published on the WWW, should provide a useful resource for studying the developmental biology and pathology of porcine testis.

\section{Materials and methods}

\subsection{Source of testis tissue}

Testis samples were taken from four mature purebred Duroc boars averaging $365.5 \pm 22.4$ days in age. The pigs were raised in a traditional breeding farm, in a pig house, under natural lighting. The animals were managed and treated humanely following guidelines established by the National Science Council, Republic of China [21]. The pigs were castrated under anesthesia using atropine $(0.05 \mathrm{mg} / \mathrm{kg}$ body weight, s.c.) and azaperone ( $0.4 \mathrm{mg} / \mathrm{kg}$ body weight, s.c.) as a pre-anesthesia treatment, followed by thiamylal sodium $(10 \mathrm{mg} / \mathrm{kg}$ body weight, i.v.) for general anesthesia. Testis specimens were dissected, rinsed with sterile saline, and then frozen immediately in liquid nitrogen for at least $1 \mathrm{~h}$, after which they were stored in a $-80^{\circ} \mathrm{C}$ deep-freezer.

\subsection{Preparation of soluble proteins}

The surface of the testis specimen was rinsed with homogenization buffer (10\% sucrose, 0.05 м Tris- $\mathrm{HCl}$ pH 6.8, $0.004 \%$ Pefabloc) and then homogenized at $20000 \mathrm{rpm}$ for 2-3 min with a homogenizer (Polytron ${ }^{\circledR}$, Kinematica, Littau, Switzerland) in the presence of homogenization buffer with a tablet of anti-protease cocktail (Roche Applied Science, Mannheim, German) per $10 \mathrm{~mL}$. The homogenates were centrifuged at $12000 \times \mathrm{g}$ for $5 \mathrm{~min}$ at $4^{\circ} \mathrm{C}$. The supernatant was further centrifuged at $90000 \times \mathrm{g}$ for $3 \mathrm{~h}$ at $4^{\circ} \mathrm{C}$, then stored at $-80^{\circ} \mathrm{C}$ for further analysis. Protein concentrations of soluble protein were quantitated following a modified Bradford method [22] using BSA as standard. The protein sample was split into aliquots of $1 \mathrm{mg}$ or $400 \mu \mathrm{g}$, dried at $4^{\circ} \mathrm{C}$ by a SpeedVac evaporator (Tokyo Rikakikai, Tokyo, Japan) and then stored at $-80^{\circ} \mathrm{C}$ for $2-\mathrm{D}$ analysis.

\subsection{Analysis of proteins by 2-D PAGE}

2-D PAGE was performed following the procedure developed by Görg et al. [23]. IEF was carried out using 18-cm Immobiline DryStrips (pH 3-10 linear, Amersham Biosciences, Uppsala, Sweden) with the IPGphor system (Amersham Biosciences). One milligram (for spot excision) or $400 \mu \mathrm{g}$ (for analyzing variation of expression) of soluble proteins was dissolved in $175 \mu \mathrm{L}$ IEF sample buffer $(9.5 \mathrm{~m}$ urea, 2\% NP40, 2\% v/v Pharmalyte 3-10, and 65 mm DTT) [24]. These were mixed well with an equal volume of rehydration buffer (8 m urea, 2\% CHAPS, and 0.5\% v/v Pharmalyte 3$10)$, then loaded onto the DryStrips with a sample cup. The DryStrip was rehydrated with sample at $30 \mathrm{~V}$ for $12 \mathrm{~h}$ and focused for $64000 \mathrm{Vh}$.

After focusing, the DryStrips were first equilibrated for $15 \mathrm{~min}$ in $15 \mathrm{~mL}$ SDS equilibration buffer $(50 \mathrm{~mm}$ Tris$\mathrm{HCl}, \quad \mathrm{pH} 8.8, \quad 6 \mathrm{~m}$ urea, 2\% SDS, $30 \%$ glycerol, and $0.002 \%$ bromphenol blue) containing $100 \mathrm{~mm}$ DTT, then followed by equilibration in $15 \mathrm{~mL}$ SDS equilibration buffer containing $250 \mathrm{~mm}$ iodoacetamide for $15 \mathrm{~min}$. The DryStrip was layered on top of a vertical 12.5\% SDS-polyacrylamide gel for the second-dimension separation using the Daltsix Vertical electrophoresis system (Amersham Biosciences). The separation was run at $15^{\circ} \mathrm{C}$ with $2.5 \mathrm{~W}$ per gel for $25 \mathrm{~min}$ followed by $9 \mathrm{~W}$ per gel until the dye front reached the bottom of the gel (typically 7-7.5 h). The 2-D SDS-PAGE standards (Bio-Rad, Hercules, CA, USA) used for $M_{\mathrm{r}}$ and $\mathrm{p} I$ calibration were hen egg conalbumin type I (76 kDa; pI 6.0, 6.3, 6.6), BSA $(66.2 \mathrm{kDa}$; $\mathrm{p} I 5.4,5.6)$, bovine muscle actin (43 kDa; pI 5.0, 5.1), rabbit muscle glyceraldehydes 3-phosphate dehydrogenase (36 kDa; pI 8.3, 8.5), bovine carbonic anhydrase (31 kDa, pI 5.9, 6.0), soybean trypsin inhibitor $(21.5 \mathrm{kDa}$; $\mathrm{pI} 4.5)$, and equine myoglobin (17.5 kDa; pI 7.0). 


\subsection{Staining and imaging of 2-D gels}

After separation, the gels were stained with colloidal CBB (Serva Electrophoresis, Heidelberg, Germany) for at least $14 \mathrm{~h}$ [25]. Following staining, the gel was neutralized with $0.1 \mathrm{~m}$ Tris/phosphoric acid ( $\mathrm{pH} \mathrm{6.5)}$ for 1-3 min, then destained with 25\% methanol. After destaining, the gels were scanned with a laser densitometer (Amersham Bioscience; software was ImageQuant) and saved as a TIFF image file for further image analysis.

\subsection{Analysis on the variation of protein expression}

Protein spots on the 2-D gels were detected and analyzed using the Melanie 3 software package (GeneBio, Geneva, Switzerland). To present variation of protein expression in mature porcine testis, 194 spots on all four 2-D gels of the four mature boar testis were quantified. The relative volume of each spot to the total volume of all spots (RVol) was generated by the Melanie 3 software to correct for differences in gel staining [26]. The RVol was used to present the expression level of a protein spot.

The variations of $\mathrm{RVol}$ of the 194 spots were calculated using the Statistical Analysis System [27]. The CV of RVol was used to express the variation.

\subsection{Protein identification by MALDI-TOF MS}

\subsubsection{In-gel digestion}

Gel plugs containing protein spots were excised from CBBstained gels and placed in Eppendorf tubes. In-gel trypsin digestion was performed according to the procedure published by Havlis et al. [28] with minor modifications. Gel plugs were washed twice with double-distilled water followed by $50 \% \mathrm{ACN}$ in $50 \mathrm{~mm}$ ammonium bicarbonate and pure ACN. The gel plugs were dried in a SpeedVac evaporator then subjected to in-gel digestion or storage at $-20^{\circ} \mathrm{C}$. For ingel digestion, gel plugs were reswollen with $20 \mathrm{ng} / \mu \mathrm{L}$ trypsin (Promega, Madison, WI, USA) in $25 \mathrm{~mm}$ ammonium bicarbonate at $4^{\circ} \mathrm{C}$ for $30 \mathrm{~min}$. Digestion was allowed to proceed for $1 \mathrm{~h}$ at $56^{\circ} \mathrm{C}$. After digestion, products were recovered by $40 \% \mathrm{ACN}$ and $1 \%$ TFA.

\subsubsection{MALDI-TOF analysis}

Digested samples were spotted directly onto a $400-\mu \mathrm{m} / 384-$ well AnchorChip sample target (Bruker Daltonics, Bremen, Germany), then an equal volume of $1 \mathrm{mg} / \mathrm{mL}$ solution of CHCA in $0.1 \%$ TFA $/ 50 \%$ ACN was added. MALDI mass spectra were obtained using a Bruker autoflex TOF mass spectrometer equipped with a 384 sample scout source (Bruker Daltonics). An external peptide calibration standard containing angiotensin II $\left([\mathrm{M}+\mathrm{H}]^{+} 1046.54\right)$, angiotensin I $\left([\mathrm{M}+\mathrm{H}]^{+} 1296.68\right)$, substance $\mathrm{P}\left([\mathrm{M}+\mathrm{H}]^{+}\right.$1347.74), bombesin $\left([\mathrm{M}+\mathrm{H}]^{+} \text {1619.82), ACTH clip 1-17([M }+\mathrm{H}\right]^{+}$
2093.09), ACTH clip 18-39([M $+\mathrm{H}]^{+}$2465.20), and somatostatin $28\left([\mathrm{M}+\mathrm{H}]^{+}\right.$3147.47) (Bruker Daltonics) was used to calibrate the instrument. Spectra were acquired in reflectron mode. Peptide masses were searched against a comprehensive nonredundant protein sequence database (NCBInr) employing the MASCOT program [29] for protein identification with search conditions of taxonomy of all entries, fixed modification of carbamidomethyl modification, mass accuracy between 50-300 ppm, and maximum one missed cleavage site. Positive identification was achieved with at least five peptides matched and with the set mass accuracy and modification when the score matched with significant probability to the protein or mixture of proteins identified.

\subsection{Construction of porcine testis protein database}

A 2-D PAGE database for porcine testis protein was constructed based on information from the results.

\section{Results}

\subsection{Separation of porcine testis proteins by 2-DE}

To analyze the protein composition of porcine testis, specimen from mature boar testis was separated by 2-D PAGE. The porcine testis reference map was obtained using data from colloidal CBB-stained gels of $1 \mathrm{mg}$ total proteins. Figure 1 shows the typical 2-D protein reference map of the porcine testis proteome obtained by using an IPG 3-10 strip and a $12.5 \%$ SDS gel. Following staining with CBB, over 400 protein spots could be detected. When comparing protein patterns on the triplicate 2-D gels of the same sample, the appearance of the protein spots was highly reproducible.

\subsection{Identification of porcine testis proteins by MS}

To provide an overview of the proteins expressed in porcine testis, 447 protein spots were excised from the 2-D gels and identified by a combination of MALDI-TOF analysis and a database search. Supplementary Table 1 lists the identified porcine testis proteins. A total of 337 spots corresponding to 256 different proteins were characterized. Despite the pig genome sequence remaining incomplete, 129 (28.9\%) protein spots could be matched to porcine proteins. The other 208 spots $(46.5 \%)$ were matched to equivalent proteins in other species including Homo sapiens, Rattus norvegicus, and Mus musculus. Numbers of peptides matched to the candidate protein sequence ranged from 5 to 43 and the sequence coverage was between 11 and $92 \%$. Although the mass spectra of 110 spots $(24.6 \%)$ were of very good quality, their identification was hampered by the incompleteness of the genome sequence database. Failure to match these spots could also imply that they are as yet unidentified. 


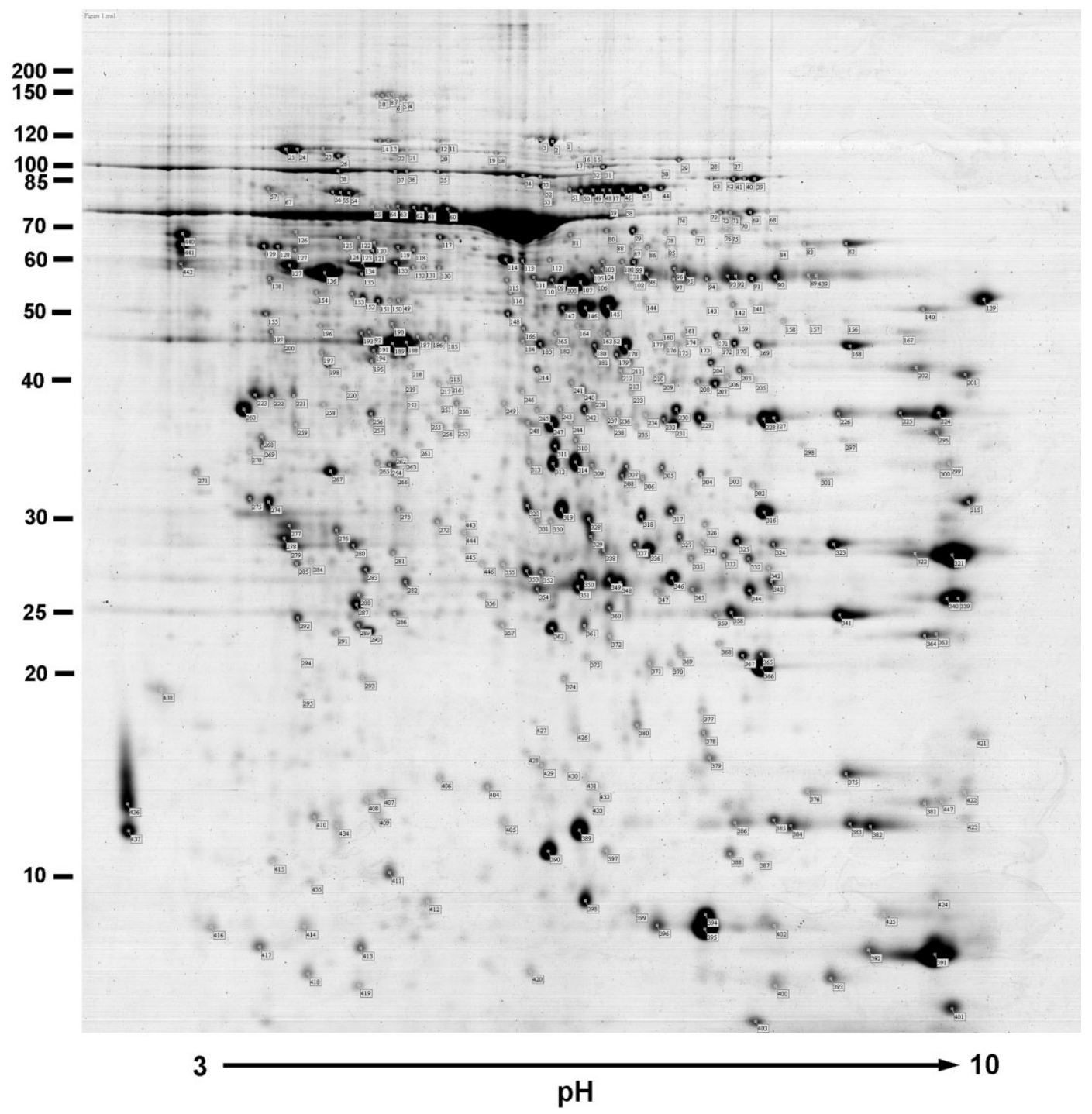

Figure 1. A representative example of a 2-D reference map of porcine testis proteins. Proteins (1 mg loaded) were separated by IEF using $180-\mathrm{mm}$, immobilized, linear pH gradient strips (IPG DryStrips) of pH 3-10, followed by $12.5 \%$ SDS-PAGE gels. Proteins were visualized by CBB staining. Spot numbers refer to Supplementary Table 1 numbers. Proteins were identified by MALDI-TOF MS.

Table 1. Classification of identified porcine testis proteins by functions

\begin{tabular}{lc}
\hline Functional category & $\begin{array}{c}\text { Percentage } \\
\text { of spots (\%) }\end{array}$ \\
\hline Cytoskeleton and cell structure (cell differentiation) & 14.9 \\
Membrane protein receptors or cell signaling related & 6.6 \\
Stress response (chaperones) & 15.5 \\
Mitochondrial and energy production related & 10.2 \\
Translational and transcriptional regulation or DNA/RNA & 5.8 \\
$\quad$ binding related & \\
Enzymes & 23.8 \\
Blood components & 12.7 \\
Others & 10.5 \\
\hline
\end{tabular}

\subsection{Characterization of the identified proteins}

To further characterize the expressed porcine testis proteins, the identified proteins were categorized by their known and/ or putative functions. More than 40 proteins were expressed as multiple spots on the reference map, demonstrating that they are isoforms. The identified proteins were divided into eight groups and are presented in Table 1. Many proteins are known to have multiple functions and their biological roles are being discovered as the knowledge of complex protein networks increases.

Of identified proteins, $14.9 \%$ are cytoskeletal and cell structure proteins, including tubulin, actin, tropomyosin, ran-binding protein 1 , vimentin, villin, destrin, transgelin, 
A

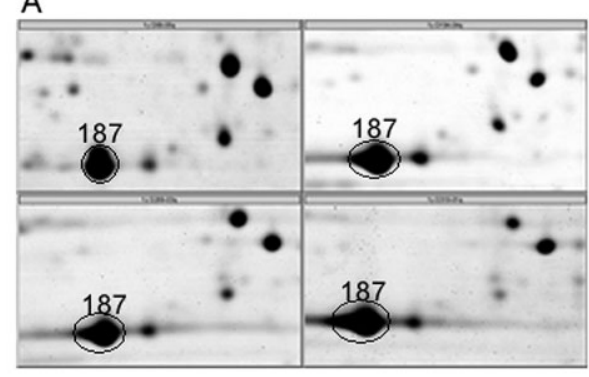

B

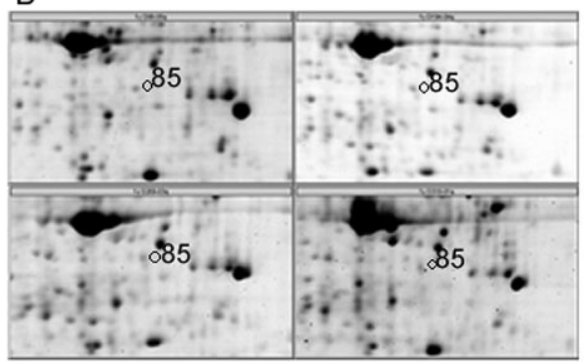

C

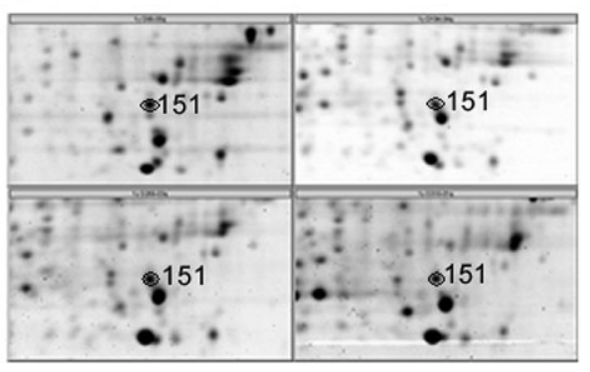

D

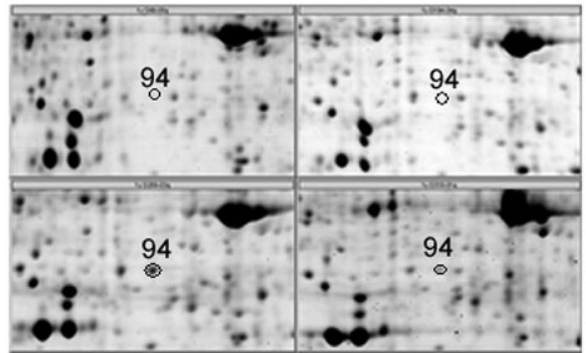

Figure 2. Zoom-in portion of 2-D gels showing the variation of expression level among individuals. (A) The protein spot with highest expression level, spot 187 (hemoglobin). (B) The protein spot with lowest expression level, spot 85 (unidentified protein). (C) The protein with lowest variation of expression level, spot $151 \quad$ (s-receptor kinase or RAB3D). (D) The protein with highest variation of expression level, spot 94 (an unidentified protein). peptidyl-prolyl cis-trans isomerase A, stathmin-1, profiling I, and F-actin capping protein. Membrane receptor proteins and signal transduction protein account for $6.6 \%$ of identified proteins, including vinculin, programmed cell death 6 interacting protein, serine/threonine protein phosphatase 2A, annexin II, annexin V, chloride intracellular channel protein 1, calmodulin, and various kinases. Stress response proteins, such as HSP $90 \mathrm{kDa}, 70 \mathrm{kDa}, 60 \mathrm{kDa}, 10 \mathrm{kDa}$ and glucose regulated-protein 94 and $78 \mathrm{kDa}$, comprise $15.5 \%$ of identified proteins. Enzymes associated with mitochondria and energy production (10.2\%) include transitional ER ATPase, guanine monophosphate synthetase, succinyl-CoA transferase, pyruvate kinase, citrate synthase, isocitrate dehydrogenase, carbonyl reductase, and carbonic anhydrase. Proteins related to translational and transcriptional regulation or DNA- and RNA-binding proteins, such as DNA polymerase, polypeptidyl-tRNA translocase, ribonuclease inhibitor, translation elongation factor EF-Tu precursor, UNRinteracting protein, and RNA-binding protein, account for $5.8 \%$ of identified porcine testis proteins. Other enzymes account for $23.8 \%$ of protein spots and included aconitase, ATP sulfurylase, alpha enolase, prolyl 4-hydroxylase, dehydrogenase, spermidine synthase, rhodanese, glutathione $S$ transferase, and superoxide dismutase. In total, $12.7 \%$ of protein spots, including transferrin, serum albumin precursor, albumin, immunoglobulin, hemoglobin, cytochrome, and apolipoprotein, were from blood. The assortment of "other proteins" amounted to $10.5 \%$ and included selenium-binding protein, alpha-s-HS-glycoprotein precursor, leukocyte elastase inhibitor, tyrosine 3/tryptophan 5monooxyogenase activation protein, cortexillin II, cofilin, galectin-1, and nuclear transport factor.

\subsection{Variation in the protein expression of porcine testis}

A total of 194 spots on each 2-D gel of four mature porcine testis were quantified and used to elucidate the variation of protein expression. Figure 2 shows the zoom-in portions of some spots in all gels for visualizing the variation among samples. The mean of RVol of the 194 spots generated by the Melanie 3 program ranged from 0.014 to $7.840 \%$ and their distribution is shown in Fig. 3. The expression levels of approximately $85 \%$ of detected protein spots were below $1.0 \%$ RVol. The protein with highest expression level was hemoglobin $(7.840 \pm 0.995 \% \mathrm{RVol})$ and the lowest was an unidentified protein $(0.014 \pm 0.004 \mathrm{RVol})$. The variation of expression level of quantified porcine testis proteins ranged from 4.7 to $131.5 \%$, with $83 \%$ of spots detected at variation levels lower than $60 \%$ (Fig. 4). The protein with the highest variation of expression level was an unidentified protein $(\mathrm{CV}=131.5 \%)$, and the lowest was s-receptor kinase or $\mathrm{RAB3D}(\mathrm{CV}=4.7 \%)$.

\subsection{Construction of a 2-D database for porcine testis proteins}

The protein identity data generated in this study were used to construct a web-based protein reference database of the porcine testis. The database can be found at the research institute website (http://www.atit.org.tw). The database comprises 2-D PAGE images in small and large formats and click-accessible information on protein identities. The small image was used for a quick, convenient overall view of the protein expression pattern. The large image presented 


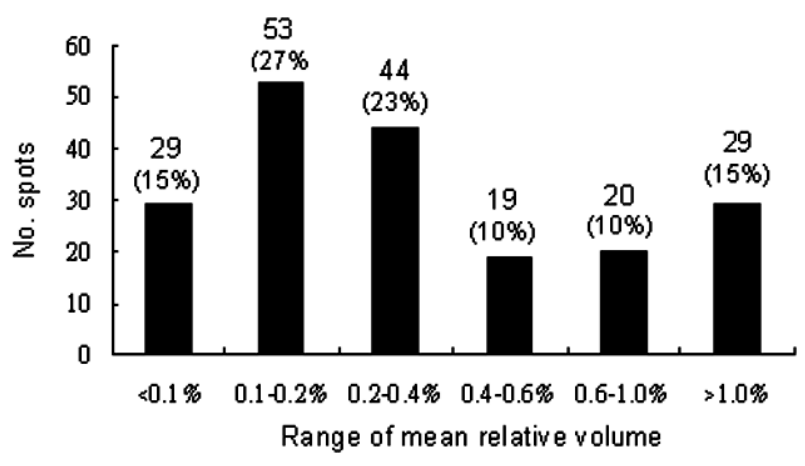

Figure 3. Distributions of the range of the mean relative volume of 194 protein spots on 2-D gels from four mature boars. The protein spots on the 2-D gels were detected and analyzed using the Melanie 3 software package. A total of 194 spots on all four 2-D gels were quantified and their relative spot volumes generated. The relative volume of a spot was used to present the expression level of a protein spot. Figures in parentheses represent percentages of total spots in the category.

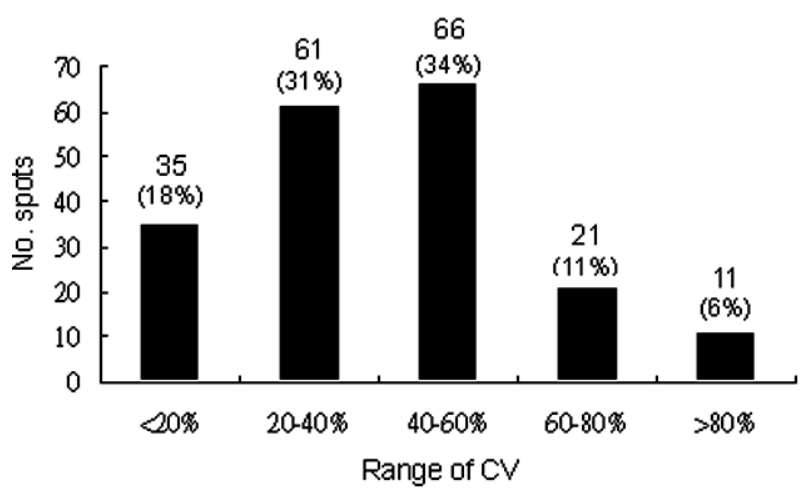

Figure 4. Distributions of the range of $\mathrm{CV}$ of the relative volume of 194 protein spots on 2-D gels from four mature boars. Protein spots on the 2-D gels were detected and analyzed with the Melanie 3 software package. A total of 194 spots on all four 2-D gels were quantified and their relative spot volumes generated. Figures in parentheses represent percentages of total spots in the category.

details of the porcine testis protein. Protein spots with known identity were featured as clickable to connect with their matching information in GenBank. This database will be extended into a reproductive proteome database for pigs as the reference maps of other reproductive organs, tissues, and/or cells are completed in the near future.

\section{Discussion}

The testis is essential to male reproduction. The major functions of the testis include synthesis of male sex hormone, androgen, and production of the male gametes, spermatozoa. While several studies have compared protein expression in rodent meiotic and post-meiotic germ cells, few studies examined the proteome of the whole testis. A comprehensive understanding of proteins expressed in the testis will provide biological information of many reproductive disorders in males. Developments in proteomic techniques have considerably enhanced the mapping of protein expressions in reproductive tissues [15]. This study applied a proteomic approach to investigate the protein composition and to establish a 2-D PAGE reference map for porcine testis proteins. More than 400 proteins with a $\mathrm{p} I$ of $\mathrm{pH} 3-10$ and $M_{\mathrm{r}}$ of 10-200 kDa were detected. The protein expression varied among individuals with a CV between 4.7 and $131.5 \%$. Altogether 447 spots were excised for protein identification, among which 337 proteins spots were positively identified by searching the mass spectra against the NCBInr database. A 2-D PAGE database for porcine testis protein was constructed based on the results. This database should be valuable for studying the developmental biology and pathology of porcine testis.

Interactions between germ cells and Sertoli cells are pivotal to the completion of normal spermatogenesis [30, 31]. These interactions are primarily formed by proteins and peptides produced by both germ-cell and somatic-cell components of the seminiferous epithelium [32, 33]. Although several studies examined the gene expression [34, 35] or compared protein components in isolated meiotic and postmeiotic germ cells [17, 18, 36, 37], the biology of the testis remains obscure. Exploring differential protein expression in the testis at different developmental stages or in reproductive disorders will help in the understanding of the biology of the testis and the improvement of male fertility. To facilitate these goals, a proteomic approach was applied for investigating protein composition and a 2-D PAGE database was constructed for normal mature porcine testis proteins.

Application of IPG strips with a $\mathrm{pH}$ range 3-10 and $12.5 \%$ SDS-PAGE proved quite efficient for the majority of spot detection (Fig. 1). The $M_{\mathrm{r}}$ of detected proteins ranged from 10 to $200 \mathrm{kDa}$. The smallest protein identified was the $15-\mathrm{kDa}$ co-chaperone P23 and the largest protein identified was $117-\mathrm{kDa}$ vinculin. The variation of protein expression revealed that the mean of RVol ranged from 0.014 to $7.840 \%$ (Fig. 3) with a CV between 4.7 and 131.5\% (Fig. 4). The proteins with high variation may be due to low-abundant proteins at the detection limit (Fig. 2). The physiological function of the differentially expressed proteins needs further exploration.

PMF was used to analyze the 447 excised protein spots from porcine testis. Of these proteins, 337 were identified (Supplementary Table 1) and categorized into eight functional classes (Table 1). Among the identified protein spots, 93\% (313 spots) have been previously reported to be present in the testis [38]. In total, $18.4 \%$ (62 spots) of the identified spots are testis specific [39]. These proteins (Supplementary Table 1) were reported to be involved in spermine and spermidine synthesis, DNA or RNA binding, steroid synthesis, gap junction components, sperm structure, or expressed as testis isoform. Four protein spots were matched to the proteins of quite distant species, including DNA polymerase of 
Thermoplasma volcanium, fructose-6-phosphate-2-kinase/ fructose-2,6-bisphosphatase of Oryza sativa, Chaperonin GroEL of Burkholderia fungorum, and alpha-tubulin of Mnemiopsis leidyi. These proteins might have an important function, and thus they were conserved in the phylogenetically distant species. However, there is still the probability of a random match. Further verification of the identity of these spots by sequence tagging is needed.

On the 2-D PAGE reference map (Fig. 1), some proteins are represented by multiple spots. Examples are HSP90 alpha, represented by at least five spots, and peptidyl-prolyl cis-trans isomerase A, represented by at least three spots. The multiple spots may result from phosphorylation, glycosylation, or other PTM. However, the biological significance of these heterogeneities remains uncertain.

Studies on testis protein expression at various developmental stages and under different physiological conditions are thematically central when exploring porcine reproduction. These aspects were the major objectives underlying laboratory work in the present study. Among identified proteins in this investigation, many were housekeeping proteins, including structural proteins and several redox enzymes. Some proteins have been described as present in the testis or in testicular cells, e.g., carbonyl reductase [40, 41], phosphatidylethanolamine-binding protein [42], ubiquitin carboxy terminal hydrolase T [43], HSP90 [44, 45], testisspecific heat shock protein-related gene hst70 [46], HSP60 [47], testis-specific phosphoglycerate kinase [48], stathmin $[49,50]$, glutathione $S$-transferase mu [51], glutathione $S$ transferase $P[52,53]$, and translationally controlled tumor protein $[18,54]$. The expressions of these proteins in the testis and/or in isolated spermatogenetic cells imply that they play significant roles in spermatogenesis.

Tubulin is a polymorphic protein and the major component of microtubules. An earlier study revealed that tubulin plays an important role in axonemal motility [55]. The interaction of dynein ATPase with specific sites of tubulin on the microtubule wall enables sliding of the microtubules. Specifically, tubulin interacts with other axonemal and/or periaxonemal proteins that could affect flagellar beating and its regulation [56].

Stathmin is involved in various cell processes including cell proliferation and differentiation and has already been described in the testis [18, 50]. Further investigation demonstrated that stathmin is expressed in spermatogonia, intensively expressed in the meiotic spermatocytes, and also expressed in the first generations of spermatids [57]. Stathmin expression is known to be associated with microtubule dynamics. Therefore, its expression in the germ line probably relates to extremely complex structural cellular rearrangements in germ cells during spermatogenesis [57].

HSP expression has been demonstrated during the postnatal development of spermatogenetic cells and is considered crucial for spermatogenesis $[58,59]$. In mouse testis, one of the most abundant developmentally regulated proteins is HSP70-2 [60]. Targeted disruption of the mouse
HSP70-2 gene causes failed meiosis, germ cell apoptosis, and male infertility [58, 61, 62]. HSP70-2 has been demonstrated to be required for CDC2 kinase activity for meiosis I [63] and for desynapsis of synaptonemal complexes during meiotic prophase in mouse spermatocytes [64]. In a previous study, the present authors also discovered a developmentally expressed P70t in porcine testis as a homologous protein of rat testis-specific HSP70 (submitted for publication). Whether differentially expressed HSPs influence porcine spermatogenesis and development as in other species is now being investigated.

In conclusion, developments in proteomics offer new opportunities for assessing the molecular nature of porcine reproductive tissues including expression level, PTM, protein-protein interaction and subcellular location. This study represented the first application of proteomics for the evaluation of porcine testis. Further expansion of this database will provide a valuable resource for molecular analysis of normal and pathologic conditions affecting male reproduction. Additionally, this database and the attached information should also create a window for assessing treatment responses based on changes in the testis proteome. Moreover, the discovery of testis-specific markers may yield new tools for both selecting fertility and diagnosing reproductive dysfunctions of boars.

The authors would like to thank the National Science Council (contract nos. NSC89-2313-B-059-045, NSC90-2313-B-059002) and the Council of Agriculture (contract nos. 91AS-1.1.3$A D-U 1,92 A S-3.1 .1-A D-U 1,93 A S-3.1 .1-A D-U 1)$ of the Republic of China for financial support of this research. The autoflex MALDI-TOF mass spectrometer was purchased with support from the National Science Council (Contract No. NSC91-3112P-059-002-Y). We appreciate Dr. Ming-F. Tam for critical comments and Hsing-Hsing Chen, Meng-Ting Chung, Pao-Hsieh Lin, and Ming-Yu Chen for their technical assistance.

\section{References}

[1] Christensen, A. K., in: Hamilton, D. W., Greep, R. O. (Eds.), Handbook of Physiology, Section 7, Endocrinology, Vol. V, Male Reproductive System, American Physiological Society, Washington DC 1975, pp. 57-94.

[2] Desjardins, C., J. Anim. Sci. 1978, 47 (Suppl. II), 56-79.

[3] Berardinelli, J. G., Allrich, R. D., Ford, J. J., Christenson, R. K., Anderson, L. L., Biol. Reprod. 1984, 31, 541-547.

[4] Van Straaten, H. W. M., Wensing, C. J. G., Biol. Reprod. 1978, 18, 86-93.

[5] Ford, J. J., Christenson, R. K., Maurer, R. R., Biol. Reprod. 1980, 23, 583-587.

[6] Peyratt, J. P., Meusy-Dessolle, N., Garnier, J., Endocrinology $1981,108,625-631$.

[7] Ford, J. J., Proc. Soc. Exp. Biol. Med. 1983, 174, 160-164. 
[8] Allrich, R. D., Christenson, R. K., Ford, J. J., Zimmerman, D. R., Biol. Reprod. 1983, 28, 902-909.

[9] Hecht, N. B., in: Desjardins, C., Ewing, L. L. (Eds.), Cell and Molecular Biology of the Testis, Oxford University Press, New York 1993, pp. 400-432.

[10] Wilkins, M. R., Sanchez, J. C., Gooley, A. A., Appel, R. D. et al., Biotech. Gen. Eng. Rev. 1995, 13, 19-50.

[11] James, P., Biochem. Biophy. Res. Commun. 1997, 231, 1-6.

[12] Mann, M., Hendrickson, R. C., Pandey, A., Annu. Rev. Biochem. 2001, 70, 437-473.

[13] Blackstock, W. P., Weir, M. P., TIB Tech. 1999, 17, 121-127.

[14] Pandey, A., Mann, M., Nature 2000, 405, 837-846.

[15] Brewis, I. A., Hum. Reprod. 1999, 14, 2927-2929.

[16] Boitani, C., Geremia, R., Rossi, R., Monesi, V., Cell Differ. 1980, 9, 41-49.

[17] O’Brien, D. A., Biol. Reprod. 1987, 37, 147-157.

[18] Guillaume, E., Dupaix, A., Moertz, E., Courtens, J.-L. et al., Proteome 2000, DOI 10.1007/s102160000003.

[19] Huang, S. Y., Kuo, Y. H., Lee, W. C., Tsou, H. L. et al., Theriogenology 1999, 51, 1007-1016.

[20] Huang, S. Y., Kuo, Y. H., Lee, Y. P., Tsou, H. L. et al., Anim. Reprod. Sci. 2000, 63, 231-240.

[21] National Science Council, Handbook of Management and Use of Laboratory Animals. Taipei, Taiwan, R.O.C. 1993.

[22] Peterson, G. L., Methods Enzymol. 1983, 91, 95-119.

[23] Görg, A., Obermaier, C., Boguth, G., Harder, A. et al., Electrophoresis 2000, 21,1037-53.

[24] O'Farrell, P. H., J. Biol. Chem. 1975, 250, 4007-4021.

[25] Neuhoff, V., Arold, N., Taube, D., Ehrhardt, W., Electrophoresis 1988, 9, 255-262.

[26] Sanchez, J. C., Converset, V., Nolan, A., Schmid, G. et al., Proteomics 2003, 3, 1500-1520.

[27] SAS Institute, Statistical Analysis System (SAS) User's Guide: Statistics Release 6.03, ed., SAS Institute Inc., Cary, N.C., USA 1989.

[28] Havlis, J., Thomas, H., Sebela, M., Shevchenko, A., Anal. Chem. 2003, 75, 1300-1306.

[29] Perkins, D. N., Pappin, D. J. C., Creasy, D. M., Cottrell, J. S., Electrophoresis 1999, 20, 3551-3567.

[30] Jégou, B., Int. Rev. Cytol. 1993, 147, 25-96.

[31] Sharpe, R. M., in: Russell, L. D., Griswold, M. D. (Eds.), The Sertoli Cell. Cache River Press, New York 1993, pp. 391-418.

[32] Gnessi, L., Fabbri, A., Spera, G., Endocr. Rev. 1997, 18, $541-$ 609.

[33] Jégou, B., Pineau, C., Dupaix, A., in: Wang, C. (Ed.), Endocrine Update Series, vol. 5, Kluwer, Norwell 1999, pp. 41-64.

[34] Eddy, E. M., Welsh, J. E., O'Brien, D. A., in: de Kretser, D. (Ed.), Molecular biology of the male reproductive system, Academic Press, San Diego 1993, pp. 181-232.

[35] Hecht, N. B., BioEssays 1998, 20, 555-561.

[36] Cossi, G., Sanchez, J. C., Golaz, O., Wettstein, R., Hochstrasser, D. F., Electrophoresis 1995, 16, 1225-1230.

[37] Cossi, G., Sanchez, J. C., Wettstein, R., Hochstrasser, D. F., Electrophoresis 1997, 18, 548-552.
[38] Rockett, J. C., Christopher Luft, J., Brian Garges, J., Krawetz, S. A. et al., Genome Biol. 2001, 2, RESEARCH0014.

[39] Shima, J. E., McLean, D. J., McCarrey, J. R., Griswold, M. D., Biol. Reprod. 2004, 71, 319-330.

[40] Inazu, N., Ruepp, B., Wirth, H., Wermuth, B., Biochim. Biophys. Acta 1992, 1116, 50-56.

[41] Wermuth, B., Mader-Heinemann, G., Ernst, E., Eur. J. Biochem. 1995, 228, 473-479.

[42] Seddiqi, N., Segretain, N. D., Bucquoy, S., Pineau, C. et al., Experientia 1996, 52, 101-110.

[43] Kajimoto, Y., Hashimoto, T., Shirai, Y., Nishino, N. et al., J. Biochem. 1992, 112, 28-32.

[44] Gruppi, C. M., Wolgemuth, D. J., Dev. Genet. 1993, 14, 119 126.

[45] Huang, H. C., Tsay, C. C., Yu, J. S., Lin, J. H. et al., J. Protein Chem. 2002, 21, 111-121.

[46] Wisniewski, J., Kordula, T., Krawczyk, Z., Biochim. Biophys. Acta 1990, 1048, 93-99.

[47] Meinhardt, A., Parvinen, M., Bacher, M., Aumuller, G. et al., Biol. Reprod. 1995, 52, 798-807.

[48] Erickson, R. P., Michelson, A. M., Rosenberg, M. P., Sanchez, E., Orkin, S. H., Biosci. Rep. 1985, 5, 1087-1091.

[49] Schubart, U. K., J. Biol. Chem. 1988, 263, 12156-12160.

[50] Amat, J. A., Fields, K. L., Schubart, U. K., Mol. Reprod. Dev. 1990, 23, 383-390.

[51] Fulcher, K. D., Welch, J. E., Klapper, D. G., O'Brien, D. A., Eddy, E. M., Mol. Reprod. Dev. 1995, 42, 415-424.

[52] Yoganathan, T., Oyen, O., Eskild, W., Jahnsen, T., Hansson, V., Biochem. Int. 1989, 19, 667-672.

[53] Veri, J. P., Hermo, L., Robaire, B., J. Androl. 1993, 14, $23-44$.

[54] Guillaume, E., Pineau, C., Evrard, B., Dupaix, A. et al., Proteomics 2001, 1, 880-889.

[55] Audebert, S., White, D., Cosson, J., Huitorel, P. et al., Eur. J. Biochem. 1999, 261, 48-56.

[56] Fouquet, J. P., Kann, M. L., Pechart, I., Prigent, Y., Tissue Cell 1997, 29, 573-583.

[57] Guillaume, E., Evrard, B., Com, E., Moertz, E. et al., Mol. Reprod. Dev. 2001, 60, 439-445.

[58] Sarge, K. D., Cullen, K. E., Cell. Mol. Life Sci. 1997, 53, 191197.

[59] Neuer, A., Spandorfer, S. D., Giraldo, P., Dieterle, S. et al., Hum. Reprod. Update 2000, 6, 149-159.

[60] Allen, R. L., O’Brien, D. A., Eddy, E. M., Mol. Cell. Biol. 1988, 8, 828-832.

[61] Dix, D. J., Allen, J. W., Collins, B. W., Mori, C. et al., Proc. Natl. Acad. Sci. USA 1996, 93, 3264-3268.

[62] Mori, C., Nakamura, N., Dix, D. J., Fujioka, M. et al., Dev. Dyn. $1997,208,125-136$.

[63] Zhu, P., Dix, D. J., Eddy, E. M., Development 1997, 124, $3007-$ 3014.

[64] Dix, D. J., Allen, J. W., Collins, B. W., Poorman-Allen, P. et al., Development 1997, 124, 4595-4603. 